\title{
E-tracers: Development of a low cost wireless technique for exploring sub-surface hydrological systems
}

\author{
Elizabeth A. Bagshaw, ${ }^{1 *}$ \\ Stephen Burrow, \\ Jemma L. Wadham, ${ }^{2}$ \\ James Bowden, ${ }^{1}$ \\ Ben Lishman, ${ }^{2}$ Mike Salter, ${ }^{1}$ \\ Richard Barnes ${ }^{1}$ and \\ Peter Nienow ${ }^{3}$ \\ ${ }^{1}$ Queens School of Engineering, \\ University of Bristol, Bristol, UK \\ ${ }^{2}$ Bristol Glaciology Centre, School of \\ Geographical Sciences, University of \\ Bristol, Bristol, UK \\ ${ }^{3}$ School of Geosciences, University of \\ Edinburgh, Edinburgh, UK
}

*Correspondence to: Elizabeth A. Bagshaw, Queens School of Engineering, University of Bristol, University Walk, Bristol BS8 1TR, UK.

E-mail: liz.bagshaw@bristol.ac.uk
Received 5 January 2012 Accepted 31 May 2012

\begin{abstract}
This briefing describes the first deployment of a new electronic tracer (E-tracer) for obtaining along-flowpath measurements in subsurface hydrological systems. These low-cost, wireless sensor platforms were deployed into moulins on the Greenland Ice Sheet. After descending into the moulin, the tracers travelled through the subglacial drainage system before emerging at the glacier portal. They are capable of collecting along-flowpath data from the point of injection until detection. The E-tracers emit a radio frequency signal, which enables sensor identification, location and recovery from the proglacial plain. The second generation of prototype E-tracers recorded water pressure, but the robust sensor design provides a versatile platform for measuring a range of parameters, including temperature and electrical conductivity, in hydrological environments that are challenging to monitor using tethered sensors. Copyright (c) 2012 John Wiley \& Sons, Ltd.
\end{abstract}

Key words wireless sensors; subglacial water pressure; tracing

\section{Introduction}

Many hydrological systems on Earth are remote or difficult to access and are, hence, challenging to monitor using conventional sensor technologies. This is particularly true of the Earth's ice sheets, where a pressing need to better understand the impacts of climate change makes in situ monitoring a priority. Rates of ice motion, which affect ice sheet mass balance, are highly responsive to changes in the manner in which water flows at the ice sheet bed. This is particularly true of the Greenland Ice Sheet (GrIS) where there are strong variations in meltwater supply to the ice sheet bed (Schoof, 2010). However, the structure of the subglacial drainage system beneath the GrIS is still unknown, and the relationship between ice dynamics and basal hydrology is poorly understood. There are conflicting views on the magnitude and longevity of the effect of increased meltwater volumes on basal water storage and pressures and, hence, on ice motion (Zwally et al., 2002; Schoof, 2010). Poor understanding of these relationships on the GrIS arises from the difficulty in making direct measurements of drainage system behaviour, particularly with respect to water pressure.

To date, subglacial water pressures have been measured via tethered sensors in boreholes on small valley glaciers (Hubbard et al., 1995). Such measurements are difficult to achieve on an ice sheet because of significant thicknesses $(>1 \mathrm{~km})$ of fast-flowing ice. Large moulins, which transmit high volumes of water to the ice sheet bed, are potential sites for monitoring, but high turbulence and tortuous flow paths (Fountain et al., 2005; Catania et al., 2008) may hinder the deployment of tethered sensors, and there is a relatively low probability of intersecting a major subglacial channel. In addition, data gathered by such sensors are spatially limited to a single point. Consequently, a device is required that can measure water pressure at a range of locations at the ice bed without requiring a constant physical connection with the surface. This paper presents a new electronic tracer (E-tracer) that is capable of travelling through the subglacial drainage system that will eventually measure and record 


\section{SCIENTIFIC BRIEFING}

in situ pressure as it transits. The sensor is equipped with a radio direction finding (RDF) transmitter, which allows the tracer to be located once it has emerged from beneath the ice sheet for collection of data stored on the internal, nonvolatile memory. This provides a new way of accessing the ice sheet bed and making in situ measurements, which is potentially transferable to other sub-surface environments where access problems prevent the deployment of conventional sensing technologies.

\section{Technology}

The prototype E-tracers are composed of a microcontroller, with radiofrequency (RF) and memory sub-systems contained within a spherical housing (Figure 1). Later versions of the tracer incorporate a pressure sensor. The outer shell is a 50-mm diameter acrylic mould in two halves, into which the active components are potted using an epoxy resin loaded with hollow glass spheres. The density of this composite is adjusted to produce a package with a positive buoyancy of $0.15 \mathrm{~N}$ in water, which means that the tracers 'float' just below the water surface. The RDF system is based on a commercial $10 \mathrm{~mW} 151 \mathrm{MHz}$ transmitter unit (Radiometrix), controlled by a microcontroller (PIC) to emit encoded chirps, including a frequency-modulated ASCII character, which allows location and identification of individual tracers. A helical antenna, tuned to $151 \mathrm{MHz}$ in water, is contained within the housing. The pressure sensor (Honeywell) has range of 250 PSI, captured with 10-bit precision, giving an equivalent resolution of approximately $0.17-\mathrm{m}$ water depth, which is logged to internal EEPROM memory. The microcontroller conserves power by employing sleep modes, and hence, the tracers consume an average of $0.9 \mathrm{~mW}$ of power, with a life of 3 months from a one half AA size primary lithium battery. Data are retrieved through a UART interface to a laptop after physical recovery of the tracers. The components of the tracer are all commercially available, and the component cost of each prototype unit is approximately $50 \mathrm{GBP}$ at the time of writing.

\section{Field Testing}

Field trials of a range of prototype E-tracers were conducted at the Leverett Glacier, SW Greenland $\left(67^{\circ}\right.$ $0^{\prime} 31^{\prime \prime} \mathrm{N}, 50^{\circ} 41^{\prime} 21^{\prime \prime} \mathrm{W}$ ) during August 2009, 2010 and 2011. Meltwaters from the Leverett catchment $\left(\sim 600 \mathrm{~km}^{2}\right)$ drain through a single subglacial drainage portal (Bartholomew et al., 2011). Advection and transit properties of RDF-equipped E-tracers were tested via manual release of a number of tracers containing no hydrological sensors into the supraglacial melt streams a few metres upstream of selected moulins, between 1 and $15 \mathrm{~km}$ from the glacier portal. From here, they were allowed to descend into the subglacial drainage system (Figure 2). Rhodamine dye was injected simultaneously to determine water transit times (Nienow et al., 1998). The E-tracers were recovered after emergence from the subglacial portal using two RDF detection systems: a software radio receiver (WinRadio), which logged passing tracers, installed close to the meltwater exit portal (Figure 2B), and a portable RDF animal tracking receiver (Biotrack Sika) and directional yagi antenna, which was used to manually locate E-tracers on the floodplain (Figure 2C). Pressure logging capabilities were tested via release of a tethered, pressure sensorequipped E-tracer into a moulin.

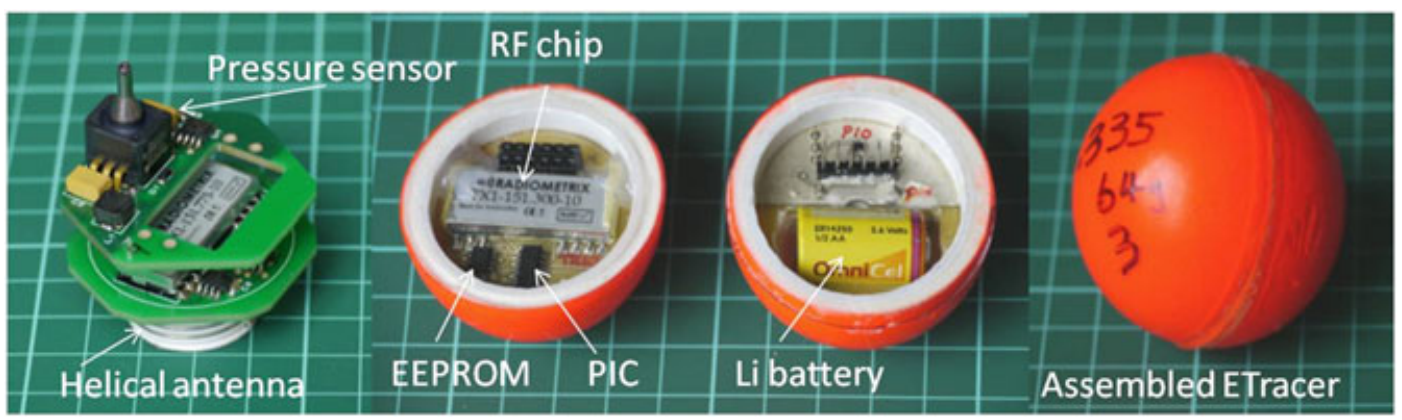

Figure 1. Electronic tracer in various stages of assembly; the background markings are $1 \times 1 \mathrm{~cm}$
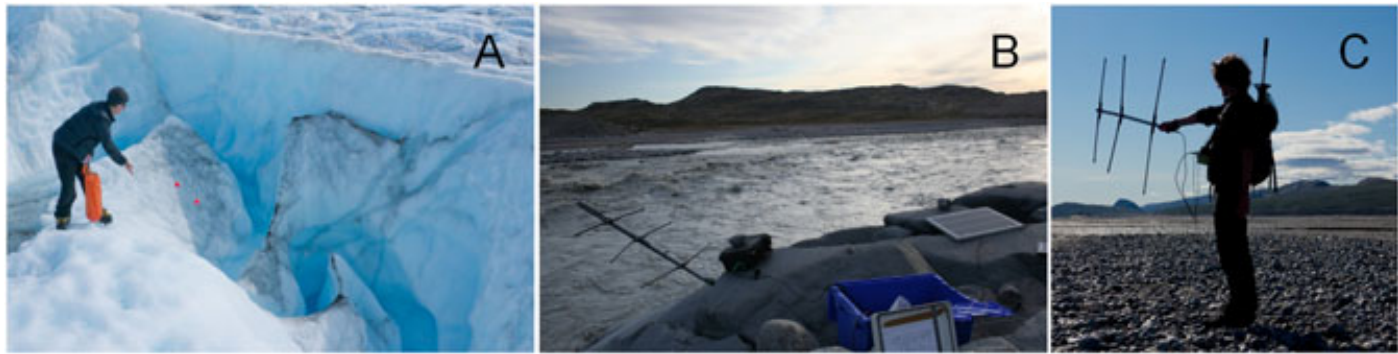

Figure 2. Deployment (a) and RDF detection of the E-tracers, using (b) the unmanned software radio listening station and (c) the rugged handheld Sika 


\section{Results and Discussion}

Range tests of the portable RDF system showed repeatable line-of-sight detection ranges of 3-5 km for a tracer floating in the proglacial meltwater stream, an order of magnitude greater than in UK trials because of lower background RF noise. The unmanned listening station (Figure 2B) allowed automated detection of E-tracers which passed when the portable RDF system was not in use. It should be noted that the received signal strength required for RDF operation is several orders of magnitude lower than that required for reliable data transmission, but it was possible to remotely identify individual tracers via RF ASCII tags. The detection rate of all E-tracers deployed between 2009 and 2011 was variable, with 13 of the 96 deployed located upon emergence at the portal. Sensors that did emerge were easily located via RDF, and $15 \%$ of these were physically recovered. Several other RDF-equipped tracers were located in poorly accessible regions of the floodplain but were not recovered because they contained no data. Table I shows the advection time of the E-tracers and rhodamine dye during successful deployments. The tracers were advected more slowly than the meltwater, suggesting that they were delayed by flow constrictions (Fountain et al., 2005). The overall detection rate, $13.5 \%$, is comparable with animal tracking studies, where tag recovery is of the order of $10-20 \%$, for example, $17 \%$ of tags were recovered during a major study of bluefin tuna (Block et al., 2005). It confirms the need for a low-cost tracer because a proportion will be lost in transit but, nevertheless, shows that it is possible for objects to pass through the subglacial drainage system and be recovered.

Detection rates varied between different moulins, depending on the distance from the margin and the volume of water draining into the moulin. Some tracers became trapped in hydraulic features within the moulins or were retarded by subglacial water storage areas. The lower emergence and detection rate from longer traces (up to $15 \mathrm{~km}$ from the glacier margin) probably reflects the greater number of opportunities for the tracer to become lodged within the drainage system over longer flow paths.

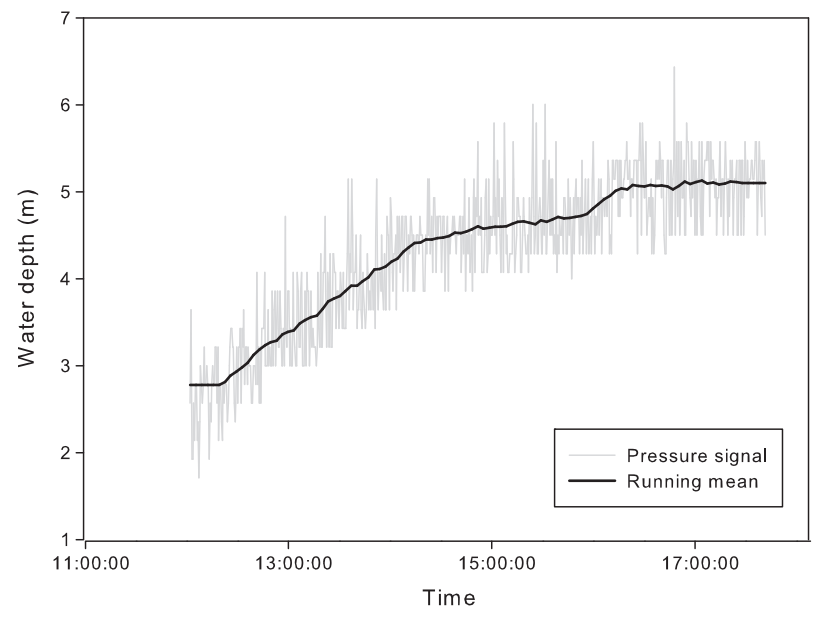

Figure 3. Pressure signal (equivalent water depth above the sensor) from a tethered E-tracer, suspended into a moulin on the surface of the Leverett Glacier. The signal fluctuates because the sensor is situated in a turbulent plunge pool, but the running mean shows the increase in meltwater entering the moulin over the course of the afternoon

Daily fluctuations of water flow into moulins (estimated via visual observation or salt dilution gauging) also affected how the E-tracers moved through the system, with low flows potentially causing tracers to become trapped in subsurface features. Figure 3 shows the water pressure recorded by a single pressure sensor-equipped E-tracer suspended into a moulin, tethered to a 50-m line. The tracer was submerged in turbulent water. The water depth increased by approximately $2 \mathrm{~m}$ over the $5.5-\mathrm{h}$ trial, as a result of increased water flow into the moulin associated with higher melt rates during the afternoon (Isenko, 2006; Werder et al., 2010).

The buoyancy of the tracers proved to be a control on the likelihood of recovery; those that were more dense transited effectively through the glacier but were unrecoverable once they emerged because they remained at the bed of the proglacial river, and those that were more buoyant occasionally became trapped within the moulins. Neutral buoyancy was, hence, selected because it resulted in a higher chance of the sensors being effectively transported and recovered. However, observations in

Table I. Flow conditions and transit time of E-tracers and rhodamine dye injected into various moulins on Leverett Glacier, 2009-2011

\begin{tabular}{|c|c|c|c|c|c|c|}
\hline Date & No. deployed & Moulin location & Distance from margin & $\%$ Detected & $\begin{array}{c}\text { Etracer } \\
\text { transit time }\end{array}$ & $\begin{array}{l}\text { Rhodamine } \\
\text { transit time }\end{array}$ \\
\hline 16 August 2009 & 10 & $6704.345 \mathrm{~N} 05008.061 \mathrm{~W}$ & $1.8 \mathrm{~km}$ & 50 & $1-2 \mathrm{~h}$ & $20 \mathrm{~min}$ \\
\hline 17 August 2009 & 14 & $6705.433 \mathrm{~N} 05000.860 \mathrm{~W}$ & $7.5 \mathrm{~km}$ & 21 & $10 \mathrm{~h}$ & $2 \mathrm{~h}$ \\
\hline 19 August 2009 & 7 & $6705.433 \mathrm{~N} 05000.860 \mathrm{~W}$ & $7.5 \mathrm{~km}$ & 0 & & \\
\hline 08 August 2010 & 5 & $6704.419 \mathrm{~N}, 05006.982 \mathrm{~W}$ & $2 \mathrm{~km}$ & 80 & $24 \mathrm{~h}$ & $1 \mathrm{~h}$ \\
\hline 11 August 2010 & 7 & $6704.345 \mathrm{~N} 05008.061 \mathrm{~W}$ & $1.8 \mathrm{~km}$ & 0 & & \\
\hline 01 August 2011 & 13 & $6705.433 \mathrm{~N} 05000.860 \mathrm{~W}$ & $7.5 \mathrm{~km}$ & 0 & & \\
\hline 02 August 2011 & 19 & $6705.420 \mathrm{~N} 05000.980 \mathrm{~W}$ & $15 \mathrm{~km}$ & 0 & & \\
\hline 05 August 2011 & 12 & $6704.419 \mathrm{~N} 05006.982 \mathrm{~W}$ & $2 \mathrm{~km}$ & 0 & & \\
\hline 09 August 2011 & 4 & $6704.341 \mathrm{~N} 05008.049 \mathrm{~W}$ & $1 \mathrm{~km}$ & 0 & & \\
\hline 11 August 2011 & 2 & $6704.284 \mathrm{~N} 0508.263 \mathrm{~W}$ & $1 \mathrm{~km}$ & 50 & $35 \mathrm{~h}$ & $1 \mathrm{~h}$ \\
\hline
\end{tabular}




\section{SCIENTIFIC BRIEFING}

summer 2011 (Table I) suggested that neutrally buoyant tracers deployed into moulins that were backed up with highly turbulent meltwater were delayed for long periods, possibly because they were retained in hydrodynamic meltwater features associated with complex moulin topography, including eddies and plunge pools (Isenko, 2006; Catania et al., 2008).

The successful recovery of a number of E-tracers from the subglacial drainage portal shows that sensors can pass through the subglacial drainage system unaided and should be capable of collecting in situ data from the glacier bed. We demonstrate that a pressure-equipped tracer is capable of logging water pressure in a moulin and will subsequently test fully functional tracers at the same site during the next field campaign. This will provide in situ water pressure data as the tracers move through the system, which can be compared with longterm surface GPS (Bartholomew et al., 2010), moulintethered water pressure measurements and proglacial stream discharge, to determine the water pressure at the bed that is associated with flow in subglacial channels. The slow transit time associated with complex hydrological flowpaths means that the E-tracers are unsuitable for determining meltwater transit times, which are better measured via more traditional dye tracing methods (Nienow et al., 1998). The potential for tracer retention beneath the glacier over long flowpaths limits the applicability of the method in very large glacier systems, but these short field trials nevertheless demonstrate a versatile sensor platform that can successfully travel through subsurface melt channels and eventually be detected, identified and recovered on emergence.

\section{Conclusions and Future Plans}

These results represent the first successful deployment and recovery of wireless sensors through the subglacial drainage system beneath the Greenland ice sheet. When combined with an integrated sensor package, the E-tracers offer exciting potential for retrieving along-flow path data, including temperature, pressure, electrical conductivity and turbidity from the englacial and basal drainage systems of glaciers and ice sheets. These data will provide a unique insight into the hydrological characteristics and drainage configuration of flow paths beneath outlet glaciers of the Greenland Ice Sheet and their spatial and temporal evolution, particularly when combined with measurements from traditional wired sensors deployed on the ice sheet and in the proglacial zone. Furthermore, when used in combination with surface GPS velocity data (Bartholomew et al., 2010), the technique will improve our understanding of coupling mechanisms between ice motion and hydrological flow routing. The technique could also be applied in other sub-surface hydrological systems, including cave systems, enabling data collection from inaccessible locations (Willden et al., 2011). They also have application in shallow marine environments, for example, in fjord monitoring. Future work will focus on the integration of sensor capability to the E-tracer prototypes. Pressure-equipped tracers will be released during a subsequent field campaign and combined with investigation of hydrodynamic effects of buoyancy on advection and the recovery of a limited quantity of data (tracer ID, maximum and mean pressure) via the automated listening station.

\section{Ackowledgements}

This research was supported by NERC grant NE/ H023879/1. Fieldwork was supported by HeliGreenland and Kangerlussuaq International Science Support. Two anonymous reviews greatly improved the manuscript.

\section{References}

Bartholomew I, Nienow P, Mair D, Hubbard A, King MA, Sole A. 2010. Seasonal evolution of subglacial drainage and acceleration in a Greenland outlet glacier. Nature Geoscience 3(6): 408-411. DOI: $10.1038 /$ ngeo863

Bartholomew I, Nienow P, Sole A, Mair D, Cowton T, Palmer S, Wadham J. 2011. Supraglacial forcing of subglacial drainage in the ablation zone of the Greenland ice sheet. Geophysical Research Letters 38. DOI: L08502 10.1029/2011g1047063

Block BA, Teo SLH, Walli A, Boustany A, Stokesbury MJW, Farwell CJ, Weng KC, Dewar H, Williams TD. 2005. Electronic tagging and population structure of atlantic bluefin tuna. Nature 434(7037): 1121-1127. DOI: 10.1038 /nature03463

Catania GA, Neumann TA, Price SF. 2008. Characterizing englacial drainage in the ablation zone of the Greenland ice sheet. Journal of Glaciology 54(187): 567-578. DOI: 10.3189/002214308786570854

Fountain, AG, Jacobel, RW, Schlichting, R, Jansson P. 2005. Fractures as the main pathways of water flow in temperate glaciers. Nature 433(7026): 618-621. DOI: 10.1038/nature03296

Hubbard BP, Sharp MJ, Willis IC, Nielsen MK, Smart CC. 1995 Borehole water-level variations and the structure of the subglacial hydrological system of haut glacier d'Arolla, Valais, Switzerland. Journal of Glaciology 41(139): 572-583.

Isenko E. 2006. Water levels and temperatures in moulins, and other hydrological observations at bashkara glacier in Caucasus, Russia, in September 2005. Japanese Bulletin of Glaciological Research 23: 95-99.

Nienow P, Sharp M, Willis I. 1998. Seasonal changes in the morphology of the subglacial drainage system, haut glacier d'arolla, Switzerland. Earth Surface Processes and Landforms 23(9): 825-843.

Schoof C. 2010. Ice-sheet acceleration driven by melt supply variability. Nature 468(7325): 803-806. DOI: 10.1038/nature09618

Werder MA, Schuler TV, Funk M. 2010. Short term variations of tracer transit speed on alpine glaciers. The Cryosphere 4(3): 381-396. DOI: $10.5194 /$ tc-4-381-2010

Wilden GC, Poole DR, Abbott BA, Green RT. 2011. Mapping boreholeaccessed karst solutional features and culvery conduits using remote sensor technology. In Proceedings of the IEEE Sensors Applications Symposium, San Antonio, 2011.

Zwally HJ, Abdalati W, Herring T, Larson K, Saba J, Steffen, K. 2002. Surface melt-induced acceleration of Greenland ice-sheet flow. Science 297(5579): 218-222. 